\title{
ArcheoSciences
}

Revue d'archéométrie

33 (suppl.) | 2009

Mémoire du sol, espace des hommes

\section{At the equator: making sense of magnetometer data}

Armin Schmidt, Robin Coningham and Prishanta Gunawardhana

\section{(2) OpenEdition}

1 Journals

\section{Electronic version}

URL: https://journals.openedition.org/archeosciences/1815

DOI: 10.4000/archeosciences.1815

ISBN: 978-2-7535-1599-4

ISSN: 2104-3728

Publisher

Presses universitaires de Rennes

\section{Printed version}

Date of publication: 30 October 2009

Number of pages: $345-347$

ISBN: 978-2-7535-0943-6

ISSN: $1960-1360$

\section{Electronic reference}

Armin Schmidt, Robin Coningham and Prishanta Gunawardhana, "At the equator: making sense of magnetometer data", ArcheoSciences [Online], 33 (suppl.) | 2009, Online since 30 October 2011, connection on 01 February 2022. URL: http://journals.openedition.org/archeosciences/1815 ; DOI: https://doi.org/10.4000/archeosciences. 1815 


\title{
At the equator: making sense of magnetometer data
}

\author{
Armin Schmidt*, Robin Coningham ** and Prishanta Gunawardhana ${ }^{* * *}$
}

Key words: Single Sensor, Total Field, Gradiometer, Vector Sensor, Sri Lanka

When undertaking magnetometer surveys in northern Europe or north America ${ }^{1}$ it hardly matters whether a vertical vector magnetometer (e.g. fluxgate) or total field instrument (e.g. caesium) is used: the anomalies are fairly similar. In fact even the difference between vertical gradiometers and single sensor instruments is not particularly large. All these instruments can be used alongside each other, and producing a combined data plot often requires not more than some amplitude scaling. However, when surveys are undertaken closer to the magnetic equator the discrepancies in the data collected with different instruments and in various configurations create challenges for the overall archaeological interpretation of results. As part of the Anuradhapura Hinterland Project in Sri Lanka (the Upper Malwatu Oya Exploration Project, UMOEP (Coningham et al., 2007) three seasons of magnetometer surveys were undertaken; two using fluxgate gradiometers and one with Caesium magnetometers in dualsensor configuration.

The aim of this paper is to review the anomalies expected from different magnetometers close to the magnetic equator and to present theoretical as well as pragmatic solution to the integration of the resulting data.

The UMOP investigates links between the ancient capital of Sri Lanka, Anuradhapura (4th $c$. BC to 11th $c$. AD) and the surrounding settlements, modelling the networks between urban and non-urban communities and the envi- ronment within the plain of Anuradhapura over the course of two millennia. To achieve this, archaeological surveys along random transects were conducted within a $50 \mathrm{~km}$ radius from the ancient citadel. Sites identified through pottery scatter or structural remains were then selected for detailed geophysical surveys and auger sampling. Based on results from these investigations small excavation trenches $\left(2 \mathrm{~m}^{2}\right.$ per site) were positioned and geoarchaeological samples taken. These explorations were underpinned by ethnoarchaeological studies that helped to formulate a theoretical framework for the archaeological interpretation of results.

Many of the geophysically investigated sites either had to be split into several small areas (e.g. individual garden plots or rice fields) or were covered in dense vegetation (chena), which made survey-logistsics difficult. Only a small and highly mobile instrument was deemed feasible for these conditions and the Geoscan FM256 fluxgate gradiometer was hence chose for the project. However, the earth's magnetic field inclination near Anuradhapura is nearly horizontal (inclination $+1.0^{\circ}$, declination $-2.5^{\circ}(\mathrm{W})$ and intensity $40516 \mathrm{nT}$; IGRF-2005), which means that away from magnetic anomalies the vertical fluxgate sensors measured hardly any signal and the instrument was hence extremely difficult to set up using the manufacturer-recommended procedure $^{2}$. A pronounced instrument drift was experienced due to high ambient temperatures and even slightly misaligned

* Archaeological Sciences, Division of AGES, University of Bradford, UK. (A.Schmidt@Bradford.ac.uk)

** Department of Archaeology, Durham University, UK.

*** Department of Archaeology, University of Kelaniya, Colombo, Sri Lanka.

1. Or Australia, south America or southern Africa, for that matter.

2. A set-up in horizontal orientation was attempted but maintaining an exact horizontal alignment while rotating through $360^{\circ}$ was impossible. It might be worth constructing a non-magnetic rig for this purpose. 


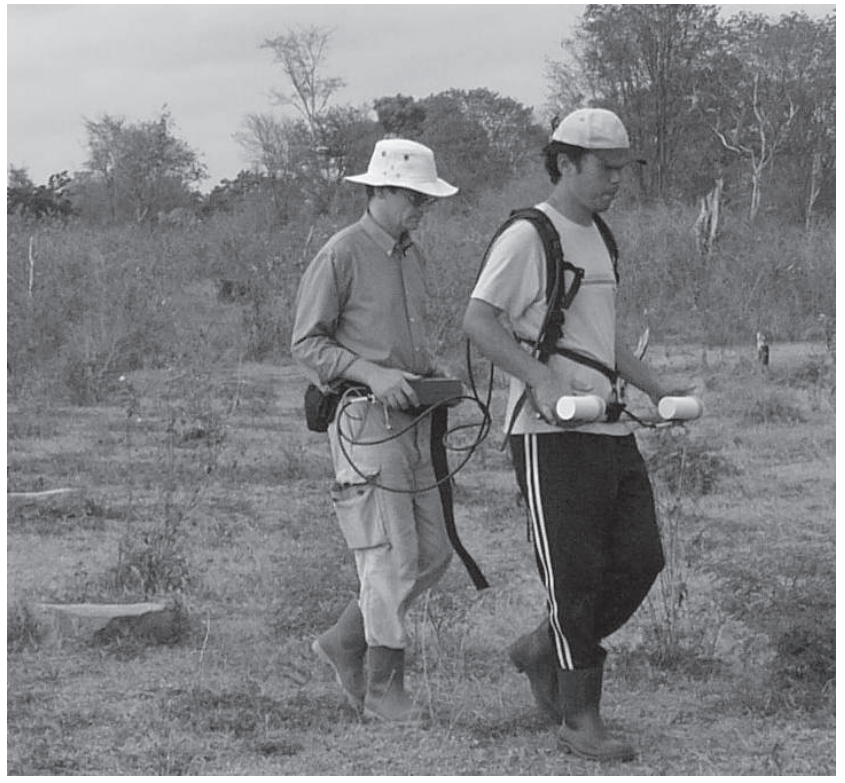

Figure 1: Geometrics G-858 in dual-sensor configuration with two operators.

sensors (heading errors) resulted in striped data. It was hence necessary to balance and align the instrument frequently, at least every two grids. This facilitated the collection of consistent data with low noise levels that allowed to discern archaeological features against a geological background. A relatively high spatial resolution $(0.25 \mathrm{~m} \times 0.5 \mathrm{~m})$ was essential to identify archaeological anomalies.

In order to eliminate the time-consuming set-up procedure, a two-sensor Caesium magnetometer was used for the third field season (Geometrics G-858). The two sensors were mounted $0.5 \mathrm{~m}$ horizontally apart to accommodate the necessary cross-line separation. It had been established earlier that such duo-sensor configuration is only minimally influence by diurnal variations over the length of a survey line (Becker, 1995; Tabbagh, 2003) and the time-saving over deployment in vertical gradiometer mode (i. e. not requiring two traverses for the same spatial resolution) was deemed significant. It is known that the ferrous content of this particular instrument's console requires a separation to the sensors of about one metre to avoid noise, and it is hence frequently deployed along a long beam (manufacturer's recommendation), on a handheld wooden frame (Fassbinder \& Gorka 2009) or mounted on a cart (Becker, 1995). However, the vegetation on the investigated sites and sensitivity to even slight heading errors made it necessary to obtain very firm control over the location of the sensor array during the survey while maintaining high manoeuvrability. The instrument was hence deployed with two operators; the front one firmly holding the sensor array and maintaining a steady pace and the rear operator carrying the console and inserting markers as directed by the front operator (Fig. 1). The two operators had to be non-magnetic and well-trained and this resource implication was nearly as restrictive as the time that was required to set up the fluxgate gradiometer in previous seasons.

As a result of the use of different instruments in contrasting configurations for the three field seasons the comparison of data became difficult across the sites surveyed. Both instruments were also tested over the same anomaly and their output was found to look very different (Fig. 2).

Land-based magnetometer surveys are usually described by magnetostatic theory and results can therefore be mathematically converted between instrument types (e.g. between vector and total field instruments) and sensor configurations (e.g. between gradiometer and single sensor) (Blakely, 1996; Tabbagh et al., 1997). However, the required frequencydomain processing is known to enhance noise levels and cannot reconstruct static offset values. To overcome these limitations processing schemes in the space - domain are evaluated for their effectiveness. The background removal effect typically associated with a gradiometer can be produced by applying a high-pass filter to single-sensor data. Nevertheless, the difference in anomaly-shape between total field and vector sensors remains significant at this low magnetic latitude. Data from a dual-sensor system can be
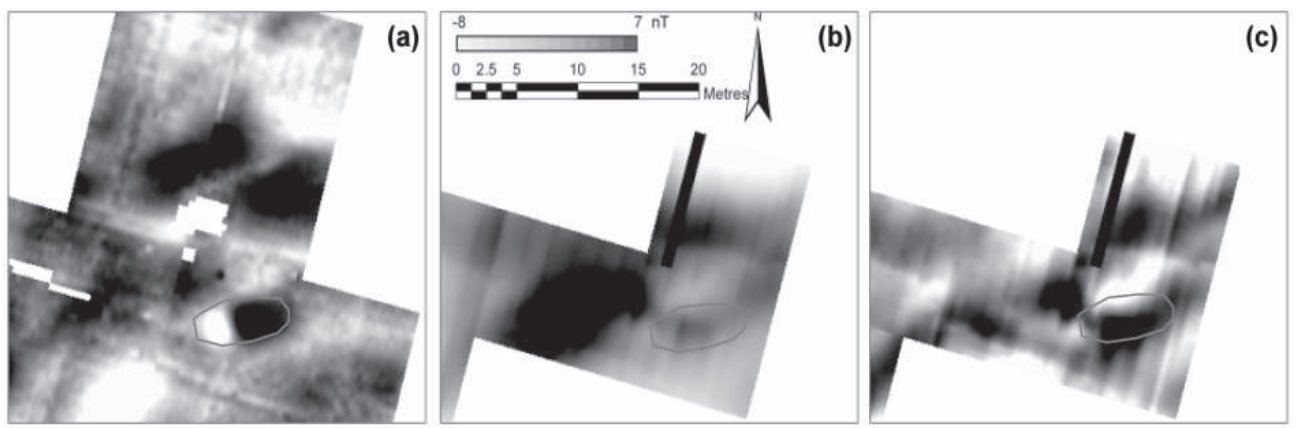

Figure 2: Magnetic anomaly (see outline) at site F102, south of Anuradhapura, Sri Lanka. (a) fluxgate gradiometer FM256, (b) Caesium total field sensors G-858 in dualsensor configuration and (c) total field data after high-pass filtering. The scale and data range is the same for all data plots (see (b). 
treated as if produced by a horizontal gradiometer (Fassbinder \& Gorka, 2009).

During a project different magnetometers may be used for various practical reasons. However, their particular properties have to be considered carefully when interpreting results. This is especially important at the magnetic equator, where data from total field and vector sensors are very different. A thorough understanding of these geophysical relationships is particularly relevant for the interpretation of archaeological anomalies and some processing steps are available to aid in this process.

\section{References}

Becker, H., 1995. From Nanotesla to Picotesla-a New Window for Magnetic Prospecting in Archaeology. Archaeological Prospection 2(4): 217-228.
Blakely, R. J., 1996. Potential Theory in Gravity and Magnetic Applications. Cambridge: Cambridge University Press.

Coningham, R., Gunawardhana, P., Manuel, M., Adikari, G., Katugampola, M., Young, R., Schmidt, A., Krishnan, K., Simpson, I., McDonnell, G., Batt, C., 2007. The state of theocracy: defining an early medieval hinterland in Sri Lanka. Antiquity 81(313): 699-719.

Fassbinder, J. W. E., GorKa, T. H., 2009. Beneath the Desert Soil - Archaeological Prospecting with a Caesium Magnetometer. In M. Reindel and G. A. Wagner (eds) New Technologies for Archaeology: 49-69. Berlin, Heidelberg: Springer.

Tabbagh, A., Desvignes, G., Dabas, M., 1997. Processing of $Z$ Gradiometer Magnetic Data Using Linear Transforms and Analytical Signal. Archaeological Prospection 4: 1-14.

TABвAGH, J., 2003. Total field magnetic prospection: are vertical gradiometer measurements preferable to single sensor survey? Archaeological Prospection 10(2): 75-81. 